\title{
Enlarged parietal foramina: a rare forensic autopsy finding
}

\author{
Carlos Durão $^{1,2,5} \cdot$ Dina Carpinteiro $^{1} \cdot$ Frederico Pedrosa $^{1}$. \\ Marcos P Machado $^{3}$. Eugénia Cunha ${ }^{4}$
}

Received: 20 May 2015 / Accepted: 17 July 2015

(C) Springer-Verlag Berlin Heidelberg 2015

\begin{abstract}
Enlarged parietal foramina (EPF) are a quite rare developmental defect of the parietal bone which has to be distinguished from the normal small parietal foramina. We report a forensic case of an individual found in an advanced state of putrefaction in his own house with an undetermined cause of death. No evidence of trauma was observed, and the toxicological exam was negative. The victim was a 40 -yearold man with a history of epilepsy. The large biparietal foramina, a rare anatomical variation and unusual autopsy finding, were observed at autopsy. The recognition of anatomical variations is important to avoid false interpretations and conclusions and has a significant potential as an identity factor, thus contributing to positive identification.
\end{abstract}

Keywords Enlarged parietal foramina $\cdot$ Parietal foramen · Catlin marks $\cdot$ Forensic anthropology

Carlos Durão

drcarlosdurao@hotmail.com

1 National Institute of Legal Medicine and Forensic Sciences, Coimbra, Portugal

2 Trauma and Orthopaedics Department, Hospital Vila Franca de Xira, Lisbon, Portugal

3 Department of Forensic Anthropology, Legal Medicine Institute Afrânio Peixoto, Rio de Janeiro, Brazil

4 Laboratory of Forensic Anthropology, Department of Life Sciences, University of Coimbra, Coimbra, Portugal

5 Orthopaedic Surgeon and Forensic Expert, Hospital Vila Franca Xira, Estrada Nacional $n^{\circ}$, Povos, 2600-009 Vila Franca de Xira, Lisboa, Portugal

\section{Introduction}

Enlarged parietal foramina (EPF), giant parietal foramina or foramina parietalia permagna, are an extremely rare [1] developmental defect of the parietal bone and are due to abnormal intramembranous ossification. They were first described in 1707 [2], and since then, the understanding of this condition has evolved substantially. In normal fetuses, the frontal, parietal, and squamous parts of the temporal bones undergo intramembranous ossification which is a direct ossification of the vascularized membrane. These bones usually ossify during the fifth month of gestation. When there is insufficient ossification around the parietal notch, they end up as large permanent foramina [2]. EPF are located in the upper posterior angle of the parietal bone close to the intersection of the sagittal and lambdoid sutures, between the posterior third and middle third of the sagittal suture [3] and are presented as symmetric, paired radiolucencies on skull radiographs. They can enable a forensic identification through comparison between antemortem and postmortem radiographs.

\section{Enlarged foramina parietalia: the state of art}

Enlarged parietal foramina are symmetrical, normally oval defects in the parietal bone situated on each side of the sagittal suture. Other used terminologies are fenestrae parietales symmetricae, foramina parietalia pragma, and Catlin marks. They can range from a few millimeters to several centimeters in diameter [2, 4], having been reported as large as $2.0 \mathrm{~cm} \mathrm{[4],}$ although the average size is under $0.5 \mathrm{~mm}$ and a size greater than $1.5 \mathrm{~mm}$ is rare. Their incidence is not that clear: Tubbs [5] reports an incidence of approximately 1 in 15,000-25,000 and a transmission through autosomal dominant inheritance. Prevalences of $1: 15,000$ to $1: 50,000$ are also reported [2]. 
The condition is distinguished from small parietal foramina which are approximately 1-2 $\mathrm{mm}$ in diameter [2], may occur both unilaterally and bilaterally, and are variable in number [6].

Broca, in 1875 [7, 8], already pointed out unusual enlargement of the parietal foramina which is due to a failure in the development of the parietal bones [9]. This neurocranial abnormality was recently reported for a Pleistocene human fossil, Xujiayao 11, in China, which constitutes the oldest evidence in human evolution of this very rare condition [10]. Because it is autosomal dominant, it can help forensic identification once the victims' relatives are aware of their existence. In some instances, these anatomical variants, covered with fibrous membrane, are associated with lambdoidal and/or sagittal agenesis [11, 12]. Although these defects are benign in the majority of cases, they can be associated with brain anomalies [11]. When associated with pathologies, which is infrequent, those can be turricephaly, cleft lip or palate, craniofacial dysostosis, broad thumb syndrome, cleidocranial dysostosis, and a syndrome consisting of hypogenitalism [12, 13]. Microphthalmia, hyperglycemia, obesity, and mental delay can also be associated [5]. Hollender [14] also mentioned craniosynostosis, whereas Tubbs [5] points to an exception where these foramina were present in a patient with Duane's syndrome. It was also reported to be associated with metopism and irregular synostosis of coronal suture [15].

Reddy and collaborators [13], when taken all these occurrences altogether, conclude that "that aberrant vascular evolution during fetal development may affect cerebrovascular, brain, or skull development." One of the most known familial cases concerns a family of 32 members in which 13 of them displayed them. Furthermore, two out of these 13 individuals had cleft lip and cleft palate [14]. Mavrogiannis et al. [16] state that heterozygous mutations of the homeobox genes ALX4 and MSX2 are at their origin. Greig $[17,15]$ who has been one of the principal authors on the subject of enlarged parietal foramina has stated that the condition is so rare that every case should be recorded, and this is one of the reasons why we think this case is worth publication.

One study $[2,5]$ reports individuals with both small and enlarged parietal foramina simultaneously. The hereditary nature of EPF as well as associated genes has been described [11]. Evidence suggests that this condition has a strong genetic heterogeneity [12].

In what concerns, EPF distribution by sex and age, unexpectedly the average size of parietal foramina in Polish females was reported to be twice as large as in males $(3.0 \mathrm{~mm}$ in females and $1.5 \mathrm{~mm}$ in males), ranging from 0.38 to $16.8 \mathrm{~mm}$ and suggesting sexual dimorphism in parietal ossification. Boyd [18] however found no difference in age or sex and stated that the average size of this foramen is less than
$0.5 \mathrm{~mm}$ and a size larger than $1.5 \mathrm{~mm}$ is rare. Reddy et al. [13] reported that this foramen can be considered enlarged when larger than $5 \mathrm{~mm}$. Circular, oval, or slit-like enlarged parietal foramina measuring several centimeters in diameter or length are rare in the literature $[2,6,19]$.

\section{Case report}

A Caucasian 40-year-old man missing for 5 days in the summer of 2014 was found in ventral decubitus with no signs of struggle at his house and was then identified circumstantially. He had a history of untreated epilepsy. Toxicology was negative, and the forensic autopsy showed the presence of enlarged parietal foramina, an atypical and rare finding (Fig. 1). The cadaver had no traumatic injuries and the cause of death was inconclusive due to the advanced state of putrefaction though it was possible to discard a violent death. As it can be seen in Fig. 1, the individual's skull retained normal sutures, namely sagittal and coronal and no craniosynostosis was noticed.

\section{Discussion}

Circular, oval, or slit-like enlarged parietal foramina measuring considerably more than a few millimeters in diameter or length are rare in the literature $[3,18]$; therefore, this is a worthwhile case report. We believe that the existence of an antemortem X-ray of the posterior vault of this individual would have been enough to corroborate a positive identification. The superimposition of ante- and postmortem X-rays, done exactly at the same position and orientation, would be a singular identity factor. The potential of such rare finding also justifies an inquiry with the nearby close relatives to
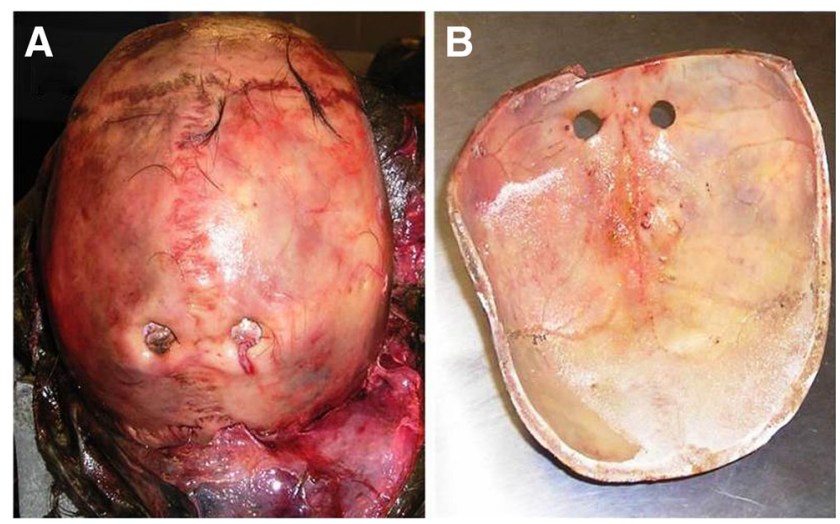

Fig. 1 Bilateral enlarged parietal foramina $(20 \times 20 \mathrm{~mm})$; a external view, b Internal skull view 
verify the existence of this condition in the family since it is often a hereditable trait [11]. In this case, it was not possible to get in touch with the family which also precluded the verification of any correlation between EPF and epilepsy.

We believe that if more cases like this are reported and discussed, the more probable will the presence of EPF contribute to a positive identification. Forensic experts really need to be aware about these anatomical variants and to do research in order to know their frequencies in populations nowadays. If rare features like this one start to be more frequently documented, we can obtain a more reliable frequency of this trait; therefore, we recommend that every case should be published. In principle, the rarer the feature is; the more probable it will contribute to identification. This is one of the reasons why we decided to call the attention to this case.

\section{Conclusion}

Enlarged parietal foramina which within developmental field disorders of the skull are classified as blastemal desmocranium [9] involve the lack of ossification of the posterior membranous parietals. They can acquire several shapes being the present ones designated as ovoid openings.

It is important that forensic experts be aware of anatomical variations and their possible clinical manifestations. Their mere presence does not necessarily imply neurological manifestations. Most EPF are asymptomatic and benign although an association with other malformations is possible. The interaction between the meninges and the scalp veins suggests an additional route to spread infection like in the case of meningitis.

Last but not the least, these foramina can, at a first glance, be confused with trepanation or gunshot wounds (GSW) because of both their size and shape. For ruling out a GSW, a detailed analysis of the edges, which are never sharp, and the absence of any type of beveling are key marks that will preclude such a classification. In what concerns the discrimination among trepanations and EPF, whereas the edges are not enough to make the distinction since they both look remodeled, their location and symmetry are signs of exclusion.

More studies in the frequencies of EPF can turn those into even better identity factors since the rarer a defect is, the more chance it has to provide identification.

\section{References}

1. Chen G, Zhang D, Feng G, Liu W, He L (2003) A novel locus for parietal foramina maps to chromosome 4q21-q23. J Hum Genet 48: 420-424

2. Griessenauer CJ, Veith P, Mortazavi MM, Stewart C, Grochowsky A, Loukas et al (2013) Enlarged parietal foramina: a review of genetics, prognosis, radiology, and treatment. Child's Nerv Syst 29:543-547. doi:10.1007/s00381-012-1982-7

3. Freire AR, Rossi AC, De Oliveira VCS, Prado FB, Caria PHF, Botacin PR (2013) Emissary foramens of the human skull: anatomical characteristics and its relations with clinical neurosurgery. Int J Morphol 31(1):287-292

4. Thompson EM, Baraitser M, Hayward RD (1984) Parietal foramina in Saethre-Chotzen syndrome. J Med Genet 21:369-372

5. Tubbs RS, Doughty K, Oakes WJ, Wellons JC (2004) Duane's syndrome and giant parietal foramina. Pediatr Neurol 30:74-76

6. Wysocki J, Reymond J, Skarżynski H, Wróbel B (2006) The size of selected human skull foramina in relation to skull capacity. Folia Morphol 66(4):301-308

7. Broca $\mathrm{P}(1875)$ Sur les trous pariétaux et sur la perforation congénitale double et symétrique des Pariétaux. Bull Mém Soc Anthropol Paris 10:326-336

8. Ortner DJ (2003) Identification of pathological conditions in human skeletal remains. Academic, San Diego

9. Barnes E (1994) Developmental defects of the axial skeleton in paleopathology. University Press of Colorado, Niwot, Colorado

10. Wu X-J, Xing S, Trinkaus E (2013) An enlarged parietal foramen in the late archaic Xujiayao 11 neurocranium from northern China, and rare anomalies among Pleistocene Homo. PLoS One 8(3): e59587. doi:10.1371/journal.pone.0059587

11. Piagkou M, Skotsimara G, Repousi E, Paraskevas G, Natsis K (2013) Enlarged parietal foramina: a rare finding in a female Greek skull with unusual multiple Wormian bones and a rich parietal vascular network. Anat Sci Int 88:175-180. doi:10.1007/ s12565-013-0173-2

12. Mupparapu M, Binder RE, Duarte F (2006) Hereditary cranium bifidum persisting as enlarged parietal foramina (Catlin marks) on cephalometric radiographs. Am J Orthod Dentofacial Orthop 129: 825-828. doi:10.1016/j.ajodo.2006.02.020

13. Reddy AT, Hedlund GL, Percy AK (2000) Enlarged parietal foramina association with cerebral venous and cortical anomalies. Neurology 54:1175-1178

14. Hollender L (1967) Enlarged parietal foramina. Oral Surg Oral Med Oral Pathol Oral Radiol Endod 23:447-453

15. Stallworthy JA (1932) Case of enlarged parietal foramina associated with metopism and irregular synostosis of the coronal suture. $\mathrm{J}$ Anat 67:168-174

16. Mavrogiannis LA, Taylor IB, Davies SJ, Ramos FJ, Olivares JL, Wilkie AOM (2006) Enlarged parietal foramina caused by mutations in the homeobox genes ALX4 and MSX2: from genotype to phenotype. Eur J Hum Genet 14:151-158

17. Greig DM (1892) Congenital and symmetrical perforation of both parietal bones. J Anat and Phyiol xxvi:187

18. Boyd GI (1930) Emissary foramina of cranium in man and the anthropoids. J Anat 65:108-121

19. Mann RW, Manabe J, Byrd JE (2009) Relationship of the parietal foramen and complexity of the human sagittal suture. Int J Morphol 27:553-564. doi:10.4067/S0717-95022009000200040 